\title{
Sobre los autores
}

\section{Ximena Triquell}

Doctora en Teoría Crítica, Universidad de Nottingham, Inglaterra. Profesora y Licenciada en Letras por la Universidad Nacional de Córdoba y Magister y Doctora (PhD) en Teoría Crítica por la Universidad de Nottingham, Inglaterra. En la actualidad se desempeña como Profesora Titular de la materia "Cine y Narrativa" en la Facultad de Artes y como Prof. Adjunta de Semiótica en la carrera de Letras de la Facultad de Filosofía y Humanidades, ambas de la UNC. Es además investigadora asistente del CONICET.

\section{Alicia Dios}

Licenciada en Artes (Orientación Artes Plásticas), Facultad de Filosofía y Letras, UBA.

Integrante del Grupo de estudios sobre arte, cultura y política en la Argentina reciente, en el Instituto de Investigaciones Gino Germani, Facultad de Ciencias Sociales, UBA.

Participa en el Proyecto UBACYT "Entre el terror y la fiesta. Producciones artísticas y medios masivos en dictadura y posdictadura" dirigido por Ana Longoni. Formó parte del comité científico-organizador de las Segundas Jornadas de discusión de avances de investigación: «Entre la dictadura y la posdictadura: Producciones culturales en Argentina y América Latina", desarrolladas en la Biblioteca Nacional, Ciudad Autónoma de Buenos Aires en octubre de 2014.

\section{María Eugenia Cadús}

Licenciada y Profesora en Artes por la Facultad de Filosofía y Letras (UBA). Doctoranda en Historia y Teoría de las Artes en la Universidad de Buenos Aires, con beca del CONICET. Se desempeña como docente universitaria en la cátedra "Teoría General de la Danza" de la carrera de Artes (FFyL, UBA). Asimismo ha sido docente invitada en diversas cátedras y seminarios sobre la danza escénica en Argentina, e integra diferentes equipos de investigación en historia y teoría de la danza y las artes escénicas, en la UNA y la UBA.

\section{Carolina Andelique}

Profesora de Historia. Facultad de Humanidades y Ciencias, UNL. Estudiante avanzada de la carrera de Licenciatura en Historia en la Facultad de Humanidades y Ciencias de la UNL. Participó como adscrita en docencia de la cátedra Sociología de la Cultura durante el segundo cuatrimestre del año 2014, desarrollando el tema: "La utilización de medios audiovisuales como materiales didácticos". Actualmente se desempeña como adscripta en investigación con el tema "Las proyecciones clandestinas del cine militante en Santa Fe 1968-1973" en el marco del Proyecto CAI+D 2011 "Las imágenes audiovisuales santafesinas y sus aportes a la historia sociocultural" dirigido Lidia Acuña, facultad de Humanidades y Ciencias, UNL. 


\section{Silvia Romano}

Doctora, Licenciada y Profesora en Historia por la Universidad Nacional de Córdoba. Es profesora titular regular de Historia Social y Económica Argentina en la Facultad de Artes e investigadora por concurso del Centro de Investigaciones de la Facultad de Filosofía y Humanidades (UNC), donde dirige un programa, proyectos y becarios de organismos científicos. Es directora del Centro de Conservación y Documentación Audiovisual (CDA-UNC) y ha desempeñado esa función en el Doctorado en Historia de la FFyH (UNC). Sus investigaciones sobre historia social, política y cultural de Córdoba han sido publicadas en artículos y libros como autora, coordinadora, compiladora.

\section{Valentina Jara}

Profesora de Letras por la Facultad de Humanidades y Ciencias de la Universidad Nacional del Litoral y estudiante avanzada de la carrera de Licenciatura en Letras de la misma facultad. Dicta los cursos de ingreso de "Lectura y escritura de textos académicos" (2014-2016) y "Ciencia, Arte y Conocimiento" (2015) de la Universidad Nacional del Litoral. Desde marzo de 2015 forma parte del Proyecto C.A.I.+D. 2011 Estructura argumental y estructura eventiva de los verbos del mocoví dirigido por la Dra. Cintia Carrió, en el que participa en proyectos de investigación, publicaciones y actividades de formación vinculadas, además, a las Políticas Lingüísticas.

\section{Betina Kesler}

Profesora de Letras por la Facultad de Humanidades y Ciencias de la Universidad Nacional del Litoral y estudiante avanzada de la carrera de Licenciatura en Letras de la misma facultad. Dictó los cursos de ingreso de "Lectura y escritura de textos académicos" (2014-2015) y “Ciencia, Arte y Conocimiento" (2015) de la Universidad Nacional del Litoral. Desde 2011 pertenece al Centro de Estudios Discursos en Sociedad (CEDIS-FHUC-UNL) como integrante del Grupo de Investigaciones Semióticas (GIS) y ha participado de diferentes actividades de formación, proyectos de investigación y publicaciones especializadas en Semiótica Narrativa y Audiovisual.

\section{Silvana Flores}

Doctora en Historia y Teoría de las Artes, Facultad de Filosofía y Letras de la Universidad de Buenos Aires (UBA). Fue becaria posdoctoral del Conicet con la investigación titulada "La influencia del modernismo y la vanguardia literaria y plástica en el proyecto continental del Nuevo Cine Latinoamericano: Ios casos de Argentina, Brasil y Cuba". Actualmente es becaria posdoctoral de la Agencia de Promoción Científica y Tecnológica, con un proyecto sobre la transnacionalidad en el cine mexicano. Es autora de El Nuevo Cine Latinoamericano y su dimensión continental. Regionalismo e integración cinematográfica (Imago Mundo, 2013) y coeditora de Cine y revolución en América Latina. Una perspectiva comparada de las cinematografías de la región (Imago Mundi, 2014). También es coautora de Una historia del cine político y social en Argentina. Formas, estilos y registros (1896-1969) y (1969-2009) (Nueva Librería, 2009 y 2010). Es miembro del Centro de Investigación y Nuevos Estudios sobre Cine (ClyNE), perteneciente al Instituto de Historia del Arte Argentino y Latinoamericano (UBA).

\section{Nildete Santana de Oliveira}

Abogada. Magister en Comunicaciones de la Universidad Federal de Río de Janeiro, se licenció 
en Derecho por la Universidad Federal de Sergipe y post-graduado de la Universidad Tiradentes. Actualmente es Doctoranda en derecho por el Uniceub, Centro Universitario de Brasilia, Brasil. Se ha desempeñado enseñando las disciplinas: Introducción al Estudio del Derecho; La hermenéutica; La Ley de Seguridad Social; Derecho Laboral y Procesal Laboral. Trabajando como Coordinador Adjunto del Curso de Derecho de Finalización del Curso - UDF Centro Universitario de Brasilia. Y ha dictado seminarios en diversos cursos de postgrado en derecho de la UDF, IESB, Unieuro, UNYAHNA entre otros.

Cuenta con experiencia en el ámbito del derecho, con énfasis en el derecho público y el trabajo, principalmente en los siguientes temas: Los derechos humanos, la seguridad social, la legislación laboral, las causas, la intimidación, la seguridad laboral, las consecuencias de propiedad, daños morales y comunicación, entre otros.

\section{Lidia Acuña}

Profesora de Historia. Magister en Sociología. Profesora titular de Sociología de la Cultura en la Facultad de Humanidades y Ciencias. Profesora titular de Antropología Cultural y Social y de Sociología en la Escuela Superior de Sanidad "Dr. Ramón Carrillo" y la Facultad de Bioquímica y Ciencias Biológicas, UNL. Docente e Investigadora en UNL.

Directora y fundadora del CIECEHC- Centro de Investigaciones en Estudios Culturales, Educativos, Históricos y Comunicacionales. Participa como investigadora y dirige diversos proyectos de investigación financiados por UNL en temáticas relacionadas a los estudios culturales, la historia y la imagen desde el año 1992. Es fundadora y directora de la Revista Culturas. Debates y perspectivas de un mundo en cambio.

\section{María Sol Baliosian}

Licenciada en Comunicación Social por la Universidad Nacional de Córdoba. Actual estudiante de la Licenciatura en cine y televisión de la Facultad de Artes de la misma universidad. Participó como adscrita en docencia de la cátedra de Semiótica, en el primer cuatrimestre de 2013 y 2014. Miembro del equipo de investigación Grupo de Estudios de la Imagen, dirigido por la Dra. Ximena Triquell. Investigadora del proyecto 2014-2015 «Nuevos sentidos y representaciones en las series de ficción de la TV Pública Argentina: Un análisis después del POFyPromCAD-TV 2010". Radicado en el Centro de Producción e Investigación en Artes (CePIA).

\section{Pablo Mariano Russo}

Licenciado en ciencias de la comunicación con orientación en periodismo, de la Facultad de Ciencias Sociales (UBA). Maestrando en Comunicación y Cultura en la misma casa de estudios.

Docente de "Taller de Producción II: realización audiovisual" y del "Seminario de producción documental" en la Licenciatura en Periodismo de la UNL. Docente del "Seminario de Cine Latinoamericano" en el ISCAA (Santa Fe). Docente en materias de las carreras de Periodismo y Locución en Eter Paraná.

Director y editor de la revista digital Tierra en Trance. Reflexiones sobre cine latinoamericano (tierraentrance.miradas.net). Integrante del grupo de acción y reflexión Rev(b)elando Imágenes, compilador de los libros Santiago Álvarez. Reflexiones, testimonios, relámpagos en un instante de peligro (Tierra del Sur, 2008), y Jorge Sanjinés y el Grupo Ukamau. Reflexiones y testimonios (Tierra del Sur, 2010) y Eduardo Coutinho. Cine de conversación y antropología salvaje (Nulú Bonsai, 2013). 
Autor de los libros El compañero que lleva la cámara. Cine militante argentino (junto al lic. Maximiliano de la Puente, Tierra del Sur, 2007); y ¿Dónde está Julio López? Prácticas estéticas en relación al reclamo de aparición con vida (Tierra del Sur, 2010). Periodista cultural, con trayectoria en radio y gráfica.

\section{Carolina Bravi}

Arquitecta y licenciada en Artes Visuales. Doctora en Ciencias Sociales. Docente investigadora de la Facultad de Aaquitectura, Diseño y Urbanismo - UNL y de la Facultad de Humanidades
Artes y Ciencias Sociales de la Universidad Autónoma de Entre Ríos. Miembro del Centro de Investigaciones en Estudios Culturales, Educativos, Históricos y Comunicacionales (CIECEHC) de FHUC UNL. Integrante del Grupo Responsable del Proyecto de Investigación Cai+d "Las imágenes audiovisuales santafesinas y su aporte a la historia sociocultural»- FHUC- UNL. Ha publicado artículos en revistas nacionales e internacionales sobre temáticas relacionadas con la significación de las imágenes, en el cine y la fotografía; los estudios visuales, la historia del arte, el diseño y la arquitectura. 